\title{
Bartolomé Herrera como rector del Convictorio de San Carlos: desarrollo, ocaso y alcances de una reforma educativa ${ }^{1}$
}

\author{
Ricardo Cubas Ramacciotti \\ Universidad de los Andes, Chile
}

Bartolomé Herrera vivió en un tiempo de cambios fundamentales en el Perú e Hispanoamérica. Nació en 1808, el mismo año en que las tropas napoleónicas habían invadido la península Ibérica desencadenando el proceso emancipador latinoamericano. A lo largo de las siguientes tres décadas el panorama político, doctrinario y económico de la región se transformó completamente.

Durante esta época Herrera fue testigo de los estragos que vivió el país producto de las continuas luchas civiles y del desorden social ocasionado por el caudillismo y por la debilidad de las instituciones republicanas. En medio de este ambiente, él tuvo la convicción de que para lograr la estabilidad necesaria para el bien común del país era indispensable la formación de una clase dirigente que se distinguiera por sus cualidades morales, cívicas e intelectuales. En este sentido, si bien Herrera tuvo una influyente participación en la política, el derecho, la diplomacia y el periodismo peruanos, tal vez sus mayores esfuerzos estuvieron concentrados en el ámbito de la educación.

En esta línea, el objetivo del presente ensayo, basado en trabajos anteriores, es hacer un análisis de los antecedentes, origen, auge, ocaso y alcances de la reforma del Convictorio de San Carlos iniciada por Herrera en 1842, como parte de su anhelo de desarrollar un proyecto educativo de largo alcance que tuviera impacto en la sociedad y en la política peruanas.

El Convictorio de San Carlos: de las reformas borbónicas a las primeras décadas del Perú independiente

El Convictorio de San Carlos de Lima fue creado dentro del marco más amplio de las reformas impulsadas por Carlos III y sus ministros. Como lo

\footnotetext{
1 El presente ensayo es una versión actualizada y muy revisada de Ricardo CUBAS RAMACCIO-TTI, "Herrera como educador: La reforma del Convictorio de San Carlos" en Fernán ALTUVE (comp.) Bartolomé Herrera y su tiempo. Lima, Sociedad Peruana de Historia - Editorial Quinto Reino, 2010, pp. 35-54.
}

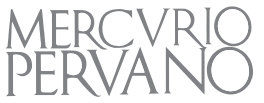


indican numerosos estudios sobre el tema, el reformismo borbónico promovió un cambio cultural que buscó superar varios de los rasgos de la tradición barroca predominantes en el imperio español para reemplazarlos por los ideales del Absolutismo Ilustrado. ${ }^{2}$ Ello suponía el desarrollo de lo que Jean Sarrailh ha llamado una "cultura dirigida", es decir, una política de Estado orientada a moldear y conducir la cultura teniendo como fin la "felicidad pública". En esa línea, la expulsión de la Compañía de Jesús de España y sus dominios en 1767 permitió a la Corona tener un control más estricto sobre los principales centros de educación superior e intervenir más directamente en la definición de sus programas de estudio. ${ }^{3}$

En este contexto, durante la administración del virrey Manuel Amat y Juniet (1761-1776) se fundó el Convictorio de San Carlos en 1770 para reemplazar a los recientemente clausurados colegios jesuitas de San Felipe y San Martín. Se pretendía hacer de esta institución la primera casa de estudios del virreinato para así formar a "buenos maestros, juristas justos y clérigos sabios y disciplinados" y para infundir una cultura ilustrada de acuerdo con las orientaciones de la Corona. Como lo indica Grover Antonio Espinoza la supervisión del gobierno virreinal sobre esta entidad fue muy estrecha:

De acuerdo con la tendencia regalista de reducir el poder de las órdenes religiosas el rector carolino, sería un clérigo secular nombrado por el virrey. Este rector estaría bajo el control de un juez protector, un oidor encargado de vigilar la marcha de San Carlos e informar al virrey. ${ }^{4}$

Desde sus orígenes hasta los años inmediatamente anteriores a la independencia, San Carlos tuvo cuatro rectores: José Laso de Mogrovejo (17701772), José de Arquella (1772-1785), Toribio Rodríguez de Mendoza (1785-1817) y Carlos Pedemonte (1817-1819). Los cuatro fueron sacerdotes seculares auspiciados por la Corona. Entre ellos, el más influyente y conocido fue Toribio Rodríguez Mendoza quien, a lo largo de sus más de treinta años de rectorado, imprimió un sello propio en la formación carolina. Junto con algunos asiduos colaboradores como el fraile Diego de Cisneros y el presbítero Mariano de Rivero y Aranívar, introdujo importantes cambios en los programas de estudio, especialmente en

\footnotetext{
2 Cfr. Jean SArrailh, La España ilustrada de la segunda mitad del siglo XVIII. México, Fondo Cultura Económica, 1974; Richard Herr, España y la revolución del siglo XVIII. Madrid, Aguilar, 1964; Mario GóngorA, "La Ilustración, el Despotismo Ilustrado y la crisis ideológica en las colonias", en Mario GóngORA, Estudios sobre la historia colonial hispanoamericana. Santiago de Chile, Editorial Universitaria, 1998, pp. 161-200; David Brading, Orbe indiano: de la monarquía católica a la República criolla, 1492-1867. México, Fondo de Cultura Económica, 1991, pp. 530-552.

3 Jean SARrailh, La España ilustrada..., p. 186.

${ }_{4}$ Grover Antonio EsPINOzA, Despotismo Ilustrado y reforma educativa: El Real Convictorio de San Carlos de Lima entre 1770 y 1817. Tesis de Licenciatura. Lima, Pontificia Universidad Católica del Perú, 1996, p. 20.
}

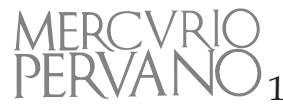


aquellas materias que suponían una orientación doctrinal. Ello se vio reflejado de manera especial en la teología, la filosofía y el derecho natural. Se criticó a la escolástica y a la educación impartida por los jesuitas. Rodríguez de Mendoza veía en las reformas educativas de Carlos III una luz que superaría las supuestas tinieblas que los miembros de la Compañía habían instaurado en los estudios a través de "raciocinios capciosos" y una metafísica aristotélica. Los discípulos de san Ignacio eran calificándolos como "guías ciegos de la ciega juventud que habían formado un reino de tinieblas"..$^{5} \mathrm{Al}$ mismo tiempo, San Carlos se convirtió en un importante foco de difusión de regalismo en el país. ${ }^{6}$

Durante las primeras dos décadas del siglo XIX, y con mayor énfasis, con la promulgación de la constitución liberal de Cádiz en 1812 y la formación de las juntas de gobierno americanas, San Carlos se empezó a asociar con ideas cada vez más cercanas al separatismo y al republicanismo. Una vez proclamada la independencia del Perú, cerca de un tercio de los primeros parlamentarios peruanos fueron antiguos alumnos o profesores de este centro de estudios y plasmaron en la constitución de 1823 las doctrinas que habían adquirido en dicha institución.

Los carolinos también ejercieron una decisiva influencia sobre la Iglesia durante los primeros años de la república. Las ideas difundidas por Rodríguez de Mendoza y Diego Cisneros formaron a un clero con tendencias regalistas y liberales. Ello contribuyó a que parte importante de los eclesiásticos peruanos apoyaran las medidas orientadas a reforzar el control político del Estado sobre la Iglesia a través del patronato. ${ }^{7} \mathrm{Al}$ mismo tiempo, las tendencias ilustradas del clero y de las élites crearon un distanciamiento de ellas frente a las prácticas de la religiosidad popular, la cual conservó una identidad cultural y espiritual barroca. Ello generó una mayor brecha social en el país que no volvería a acortarse significativamente, por lo menos en el ámbito eclesial, hasta la segunda mitad del siglo XIX.

\footnotetext{
${ }^{5}$ Rubén Vargas Ugarte, El Real Convictorio de San Carlos y sus dos luminarias. Lima, Carlos Milla Batres, 1970, pp. 71, 81-82.

${ }^{6}$ Entre los estudios que han analizado diversos aspectos académicos, intelectuales y disciplinares del Convictorio de San Carlos durante el período borbónico tardío y las primeras décadas posteriores a la independencia destacan: Fernando VALLE, “Teología, filosofía y derecho en el Perú del XVIII: Dos reformas ilustradas en el Colegio de San Carlos de Lima (1771 y 1787)", en Revista Teológica Limense, 40, 3 (2006), pp. 337-382; Grover Antonio EsPinozA, "La reforma de la educación superior en Lima: el caso del Real Convictorio de San Carlos", en Scarlett O'PHelaN Godoy (ed.), El Perú en el siglo XVIII: la Era Borbónica. Lima, Pontificia Universidad Católica del Perú - Instituto Riva-Agüero, 2015, pp. 205-244; Juan Carlos HuaraJ, "Ilustración y grados académicos en tiempos posteriores a la Independencia. De la ilustración al liberalismo", en Mercurio Peruano 524 (2011), pp. 22-50.

7 Jeffrey Klaiber, La Iglesia en el Perú. Lima, Pontificia Universidad Católica del Perú, 1988, pp. 30-31.
} 
Durante las guerras de Independencia la situación económica del Convictorio fue precaria hasta el punto que tuvo que cerrar sus aulas durante casi un año hasta su reapertura en 1822. En 1826, durante el gobierno de Simón Bolívar, San Carlos cambió su nombre por el de Convictorio Bolívar y fue dirigido por Manuel Lorenzo de Vidaurre, nombrado director por Bolívar, quien afianzó las tendencias regalistas de esta institución y buscó difundir las ideas liberales de la época. Sin embargo, Vidaurre renunció al año siguiente. Después de la Independencia, a pesar de que el gobierno en más de una ocasión intervino en el Convictorio, esta institución no logró recuperar el renombre que tuvo bajo la dirección de Toribio Rodríguez de Mendoza. ${ }^{8}$

\section{La reforma del Colegio de San Carlos}

Cuando el 28 de octubre de 1842 el presidente Francisco Vidal encargó la reforma y el rectorado del Convictorio de San Carlos al entonces joven sacerdote Bartolomé Herrera, lo hizo con la seguridad de haber encontrado una persona idónea para lograr esta empresa. ${ }^{9}$ Herrera, además de haberse destacado como educador se había hecho conocido en las más altas esferas de la política peruana debido a su precoz inteligencia y al agudo análisis que hizo de la realidad nacional en las exequias del Mariscal Gamarra.

El discurso de apertura del Convictorio del Ministro de Gobierno y Relaciones Exteriores, Benito Laso, es un testimonio de la confianza que el gobierno puso en Bartolomé Herrera y también de la urgencia y expectativas respecto a la pronta recuperación esta institución a través de una reforma pedagógica, moral y económica que la hiciese recuperar su antiguo brillo:

San Carlos yacía en el olvido, y su administración literaria, moral y económica era el desconsuelo del pueblo Limeño. Era menester un gobierno patriota [...] para que fijara su atención en un punto de tamaña importancia, cual es la educación e ilustración de la juventud y la protección del saber.

\footnotetext{
${ }^{8}$ Ricardo Cubas RamacciottI, “Educación, elites e independencia: El papel del Convictorio de San Carlos en la emancipación peruana", en Scarlett O'Phelan (ed.), La Independencia del Perú: De los Borbones a Bolívar. Lima: Pontificia Universidad Católica del Perú, Instituto Riva-Agüero, 2001, pp. 289-317. Para estudios más recientes sobre el Convictorio durante los primeros años de la república ver: Juan Carlos HuARAJ, "Izando velas hacia Ítaca: Estatuto del Convictorio de San Carlos de Lima, 1829-1839”, en Investigaciones Sociales 13, 22 (2009), pp. 283-299; Alex LoAyza Pérez, "La política educativa del Estado peruano y la propuesta educativa de los Colegios San Carlos y Guadalupe", Lima, Universidad Mayor de San Marcos, 2006.

9 El general Vidal, conoció a Herrera cuando este era cura en Lurín. Impresionado por las cualidades del joven sacerdote, hizo las gestiones para que fuera nombrado rector de San Carlos. Cfr. Gonzalo Herrera y Rodrigo Herrera, "Biografía de Don Bartolomé Herrera”, en Bartolomé Herrera, Escritos y Discursos. Lima, E. Rosay, 1929, tomo 1, p. XXXI. Ver también en: Jorge Guillermo Leguía, "San Carlos en tiempos de Herrera", en Boletín Bibliográfico de la Universidad de San Marcos, 1, 15 (diciembre, 1924).
}

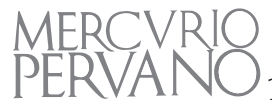


[...] Vos Señor Rector sois el primer instrumento de la voluntad del gobierno: os toca cumplirla y llenarla. Vos sois en quien descansa el gobierno y en quien el pueblo fía [... ] Señor Rector, grave, inmenso es el cargo que os encomienda: joven aún por vuestra edad, pero viejo por vuestras virtudes, por vuestros juicios y saber, os habéis constituido padre de tantos hijos. ${ }^{10}$

$\mathrm{Al}$ igual que otros hombres públicos de la época, Herrera era consciente de la enorme importancia que tenía la educación en el desarrollo del país. Consideraba que la labor aislada de algunos políticos era insuficiente para transformar la situación de crisis e inestabilidad existente. Creía, más bien, en la necesidad de moldear generaciones que por su formación espiritual y moral, y por su capacidad intelectual, estuvieran en condiciones de dirigir los rumbos del país. ${ }^{11}$ Estos objetivos fueron explicitados en la promesa que hizo en el discurso de apertura del Convictorio de San Carlos en 1842:

[...] procuraré en cuanto esté de mi parte dar buena cuenta de la confianza que en mi se deposita, al Gobierno y a los padres de familia. Los brillantes talentos y las felices índoles que brota nuestro suelo, no serán perdidos. No se malograrán los niños por falta de cultivo; ni se estragarán por falta de vigilancia en las otras... y en breve, antes de ocho años, una generación nueva saldrá de San Carlos a cegar la fuente de lágrimas que han inundado con frecuencia la República. ${ }^{12}$

Para reformar San Carlos, el Gobierno y Bartolomé Herrera dispusieron cerrar el Colegio desde noviembre de 1842 hasta el 20 de enero del año siguiente. Se nombró como visitador del Colegio al vocal de la Corte Suprema de Justicia, Manuel Cuadros, para verificar que las reformas se realizaran según las instrucciones oficiales. ${ }^{13}$

\footnotetext{
${ }^{10}$ Bartolomé Herrera, Escritos y Discursos. t., 1, pp. 36 y 38.

${ }^{11}$ De esta manera Herrera plasmó de manera práctica sus ideas respecto a lo que varios autores han denominado como la "Soberanía de la inteligencia": Cfr. Carlos Álvarez Calderón, "Bartolomé Herrera y la Soberanía de la Inteligencia", Derecho PUCP 7 (1947), pp. 32-50; Agustín DE Asís, Bartolomé Herrera, pensador político. Sevilla, Escuela de Estudios HispanoAmericanos, 1954.

${ }^{12}$ Bartolomé Herrera, Escritos y Discursos. t., 1, p. 41.

13 Herrera estaba a cargo de la reforma. La función del visitador Manuel Cuadros era de informar al gobierno acerca de las mejoras económicas y literarias de esta institución y velar que "mediante sus patrióticos esfuerzos el Colegio de San Carlos ocupe como siempre el primer lugar entre los establecimientos literarios del Perú" En: AGN. Archivo del Ministerio de Justicia (Instrucción). Años 1825-1842. Convictorios Bolívar y San Carlos. “Expediente de visita del Colegio de San Carlos-1842", legajo 179.
} 
La situación de San Carlos era muy precaria: el colegio tenía serias deudas y un déficit económico considerable, ${ }^{14}$ faltaban expedientes e información, ${ }^{15}$ el local necesitaba urgentes modificaciones y reparaciones, era necesario restablecer la disciplina en el plantel y, según Herrera, era indispensable un adelanto en los cursos, en especial, en los de letras. ${ }^{16}$

Herrera puso especial cuidado en ocuparse de todos los detalles necesarios para que este centro de estudios pudiera cumplir sus objetivos. Buscaba que los alumnos se preocuparan principalmente de su formación y quiso reducir al mínimo posibles interferencias externas como podían ser la mala alimentación, la carencia de libros o las incomodidades del local. ${ }^{17}$

Herrera contó con el apoyo económico del gobierno para mejorar la situación material de San Carlos. Así, sus instalaciones fueron reparadas y ampliadas, se reorganizó la biblioteca, y se consiguieron fondos para otorgar becas a estudiantes de escasos recursos económicos y para seleccionar nuevos profesores. Paralelamente, el nuevo rector se encargó de elaborar un nuevo reglamento que organizó el régimen de los profesores, los empleados y los alumnos, los horarios, la disciplina y la administración de las rentas. ${ }^{18}$

Dicho reglamento es una fuente valiosa para comprender algunas de las ideas que Herrera tenía acerca de lo que debía ser la formación de sus alumnos. ${ }^{19}$ Este señalaba que el fin del colegio era "la educación moral, civil y científica de los alumnos": ${ }^{20}$ el primer objetivo era la formación cristiana de la persona, el segundo la formación cívica en los valores nacionales y de respeto a las instituciones y el tercero la excelencia académica.

Los superiores y catedráticos estaban obligados a corregir las faltas de los alumnos con prudencia y a preocuparse por la disciplina que debía guardarse en el colegio, pero, ante todo, debían dar el ejemplo con su propia vida,

\footnotetext{
${ }^{14}$ El Peruano, Lima, 22 de febrero de 1843.

${ }^{15}$ Herrera notificó que no se encontraban los expedientes de la anterior visita. AGN. Archivo del Ministerio de Justicia (Instrucción). Años 1825-1842. Convictorios Bolívar y San Carlos. "Expediente de visita del Colegio de San Carlos-1842", legajo 179.

16 Bartolomé Herrera, Escritos y Discursos. t., 1, p. 40.

17 Las cartas del visitador Manuel Cuadros al ministro Benito Laso daban cuenta de la preocupación de Herrera por los detalles necesarios para crear condiciones adecuadas para los alumnos incluyendo la alimentación, la disposición de las habitaciones, que hubiera grandes ventanas para que "se renueven los aires", la limpieza del local y diversas disposiciones disciplinarias. Cfr. El Peruano, Lima, 11enero 1843 y AGN. Archivo del Ministerio de Justicia (Instrucción). Años 1825-1842. Convictorios Bolívar y San Carlos. “Expediente de visita del Colegio de San Carlos-1842", legajo 179.

${ }_{18}$ Eduardo CARrasco, Calendario y Guía de Forasteros de la República Peruana, Lima, Imprenta de Instrucción primaria, 1843, pp. 50-53.

19 Existe en la Biblioteca Nacional del Perú una copia manuscrita legalizada del primer reglamento del Colegio San Carlos elaborado y firmado por el propio Herrera. Cfr. BNP, D4698, "Proyecto de Reglamento para el Colegio de San Carlos", Lima, 1843.

${ }^{20}$ BNP, D4698, "Proyecto de Reglamento para el Colegio de San Carlos", Lima, 1843, art. 2.
}

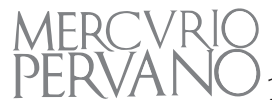


como hombres virtuosos y como profesores con una rigurosa preparación y competencia intelectual.

Una de las medidas más importantes que impulsó fue la transformación los planes de estudio. Herrera puso especial énfasis en aquellos cursos que de carácter doctrinario y filosófico. Entre ellos los principales fueron los de filosofía, derecho natural, derecho canónico y religión. Así, desterró los contenidos que eran considerados contrarios a la ortodoxia católica pero también incorporó algunos de los desarrollos intelectuales y científicos vigentes en el pensamiento europeo de su época.

Los principales cambios se dieron primero en el curso de Filosofía, en el cual se dejó de lado el texto de Heineccio, sustituyéndolo por un programa elaborado por el propio Herrera. Se reemplazaron las ideas de Condillac, Locke y de la escuela sensista por las provenientes del pensamiento tradicional católico y de las nuevas doctrinas de Francia y Escocia: “Voy enseñar yo mismo un curso de esta última ciencia (filosofía), aprovechándome de la luz que han vertido sobre ella Escocia y Francia", ${ }^{21}$ es decir por el eclecticismo de Cousin, la escuela del Common Sense de Thomas Reid ${ }^{22}$ y la metafísica de lo absoluto influenciada por Krause. Herrera citó muchas veces a los autores eclécticos como Víctor Cousin, Constant, Jouffroy, Guizot. Sin embargo, eran muchas las diferencias que lo separaban de ellos ${ }^{23}$ y tanto en las "Tablas de Materias cursadas" como en escritos posteriores se criticó a estos autores. Herrera tomó de los eclécticos su ataque a la Ilustración y a la Revolución Francesa, junto con su reivindicación de la religión, pero no asumió todos sus postulados. ${ }^{24}$ Más bien, en los cursos hubo una notable influencia de la tradición católica: los padres de la Iglesia, Santo Tomás, los escolásticos y Jaime Balmes.

El curso de Filosofía del espíritu humano fue concebido con un fin práctico. Sus contenidos buscaron brindar a los alumnos las herramientas intelectuales necesarias para que se ejercitaran en el pensar de manera metódica y lógica,

\footnotetext{
${ }^{21}$ Bartolomé Herrera, Escritos y Discursos. t., 1, p. 40.

${ }^{22}$ Herrera tomó el realismo metafísico y filosófico de la escuela escocesa. En los programas del curso de filosofía se tomaron ideas de Douglas Stewart (1753-1828) para el curso de Filosofía Moral. Stewart fue uno de los principales seguidores de Reid y un representante destacado de la escuela del Common Sense. Ver COLEGIO dE SAN CARLOS, Tabla para el examen a que se presentan los alumnos del Colegio San Carlos. Lima, Imprenta del Colegio, Lima, 1843, p. 45.

23 "Mientras la obra de Cousin no reconocía a un Dios con las características que señala el dogma católico, en Herrera son firmes estas ideas. Si los franceses sostenían la unidad de todos los órdenes, Herrera distingue el mundo objetivo como regido por leyes inalterables y el subjetivo en el que nos movemos los humanos. Es decir, la ley eterna y natural adquiere, en la obra de aquel, clásicos contornos escolásticos." Agustín DE Asís, Bartolomé Herrera... p. 36.

24 Las críticas a Cousin pueden verse en: Colegio de SAN CARLos, Tabla para el examen a que se presentan los alumnos del Colegio San Carlos. Lima, Imprenta del Colegio, Lima, 1846, p. 50. También en Bartolomé HerrerA, Tratado de Teodicea. Arequipa, Imprenta del colegio Seminario de San Jerónimo, 1872, pp. 29-31 y 46-47.
} 
reconocer las falacias y la falsedad en los raciocinios, distinguir las facultades y tendencias de la naturaleza humana y ser conscientes de sus deberes morales para ponerlos en práctica. ${ }^{25}$ Es posible resumirlo en dos elementos principales: pensar con método para buscar la verdad y conocer lo bueno para vivirlo.

En el estudio de la Filosofía moral, se sostuvo que la libertad constituía la personalidad y el origen de la moralidad. Se definieron los principales apetitos del ser humano y la manera de cómo debían ser orientados para que no se convirtieran en vicios. Además de los apetitos, los cuales eran considerados innatos, en el curso se explicaban las principales inclinaciones de la voluntad y los afectos humanos, y como debían ser dirigidas. Se sostenía que la persona tiene la capacidad de discernir entre el bien y el mal, pues la ley moral estaba inscrita en la naturaleza humana. Es en ella donde nacen los principales deberes de la persona: para consigo mismo (deberes para con el alma, respecto del entendimiento, la voluntad y la libertad; deberes para con el cuerpo), con el género humano (con los hombres en particular, con el Estado y con la familia) y para con Dios. La búsqueda del bien debe conducir a la persona hacia la vivencia de la virtud y el rechazo de los vicios. La virtud y el bien moral conducen a la persona hacia la verdadera felicidad. Un aspecto fundamental en la filosofía moral de San Carlos fue el sostenimiento de la existencia de Dios. Se planteaba que debido a que Dios es el autor de la ley natural, existe también una inclinación religiosa en todo ser humano, la cual es un poderoso auxilio de su inclinación moral. En ese sentido, toda la ley moral se resumía y encontraba su plenitud en el amor a Dios. ${ }^{26}$

La transformación de los contenidos de la cátedra de Derecho Natural fue otra de las prioridades de la reforma por contener las bases filosóficas sobre las cuales se sustentaba todo el desarrollo jurídico posterior. Suponía una concepción filosófica del hombre, una definición acerca del origen de la sociedad y de los derechos esenciales, tanto individuales como sociales, de la persona humana. En 1842 todavía estaban vigentes las obras de Heineccio, importante compilador de Pufendorf, en esta materia. El joven rector lo reemplazó por Ahrens a través de los textos del comendador Pinheiro Ferreyra. Estos autores rechazaban el iusnaturalismo de bases racionalistas y reivindicaban el papel de la metafísica en la justificación de los principios jurídicos fundamentales. Al mismo tiempo se criticó duramente las teorías de Hobbes, Rousseau y Bentham.

En el curso reformado de Derecho Natural de San Carlos se postulaba que el origen del derecho natural se encuentra en el nacimiento mismo del espíritu

\footnotetext{
${ }^{25}$ Herrera postulaba que el objeto de la Ética era "la dirección de la voluntad en el cumplimiento del deber" y que debía tener un fin eminentemente práctico, capaz de ser aplicado en la vida cotidiana. BARTolomé Herrera, Tratado de Lógica. Arequipa, Imprenta del Colegio Seminario de San Jerónimo, 1871, p. 6.

${ }^{26}$ Colegio de SAN CARlos, Tabla para el examen a que se presentan los alumnos del Colegio San Carlos. Lima, Imprenta del Colegio, Lima, 1848, pp. 49-50.
}

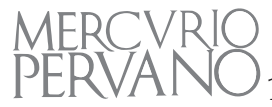


filosófico, y se relacionaba profundamente con el estudio de la naturaleza humana. En el programa se postulaba la existencia de un orden y una ley natural que se encuentra inscrita en la naturaleza humana. Ella comprende cuatro cualidades fundamentales: la primera es la de ser persona, por lo cual el ser humano es capaz de derecho, la segunda es la igualdad esencial de todos los hombres y su desigualdad accidental, la tercera es la libertad, por la cual el hombre se constituye en un ser moral y la cuarta la sociabilidad que es la facultad de la persona de vivir en sociedad ${ }^{27}$ y también de nacer y desarrollarse en una familia. La sociedad entonces nace no del pacto sino de la naturaleza humana y la familia es una institución de derecho natural. La cátedra planteaba la existencia de un orden objetivo y de principios absolutos que tienen su origen en Dios y que el hombre debía guiarse por las normas que se derivaran de él para así responder con fidelidad a su propia naturaleza.

Las ideas acerca del derecho natural impartidas en San Carlos pueden resumirse en las palabras de Herrera:

Que á mas de las verdades continjentes y variables, hai para la razón otras necesarias y absolutas; hai eternidad; hai Dios, y hai lei suprema que todo lo gobierna: Que esta lei de que es parte lo que se llama derecho, no nace del amor de sí mismo, ni de ningun acto de las voluntades creadas, sino de la naturaleza de las cosas, ó mas bien, de los principios absolutos y de la razon divina[ $\left[. .{ }^{28}\right.$

Así se planteaba que el derecho, tiene un carácter moral indestructible, pero se diferencia de la ética en que este (el derecho) envuelve la facultad de emplear en algunos casos la fuerza.

A partir de estos conceptos básicos, el programa contemplaba las relaciones existentes entre el derecho natural y la política y las implicancias sociales de una concepción u otra del derecho natural. Teniendo claros los principios del derecho natural, el marco jurídico de la sociedad tendría un carácter opuesto del derivado del iusnaturalismo racionalista: la idea de democracia, de familia, de soberanía, de Estado, de bien común, de libertad y de los deberes y derechos del hombre.

Teniendo como base lo enseñado en la cátedra de derecho natural, el curso de derecho constitucional introdujo los principios políticos y jurídicos que tenían que ver con la organización del estado y los conceptos de soberanía. En esta cátedra se defendieron las ideas políticas de Herrera y se planteó su concepción del Perú, del estado, de la soberanía y de los poderes públicos. Más que el estudio de las constituciones vigentes, se buscó hacer un análisis comparado de

27 Colegio de San Carlos, Tabla para el examen a que se presentan los alumnos del Colegio San Carlos. Lima, Imprenta del Colegio, Lima, 1843, p. 48.

${ }^{28}$ Bartolomé Herrera, Escritos y Discursos. t., 1, p. 68. 
las teorías constitucionales y ofrecer un modelo teórico que pudiera ser aplicado en el país. En el curso primeramente se definieron como nociones preliminares conceptos fundamentales como Nación, ${ }^{29}$ Estado $^{30}$ y se relacionó su origen con el derecho natural. Luego se definieron cada uno de los poderes (ejecutivo, legislativo, judicial y conservador) y el régimen de elecciones.

La reforma de la enseñanza del derecho canónico fue otra de las prioridades de Herrera. Uno de los objetivos del rector de San Carlos fue combatir las tendencias regalistas de la época y extirparlas de raíz del Convictorio y a la vez fomentar la obediencia y fidelidad al Romano Pontífice. El regalismo defendía la autonomía de los obispos frente al Papa y la curia romana y al mismo tiempo la capacidad de los gobiernos de intervenir en asuntos propiamente eclesiásticos, tendiendo así a crear una Iglesia Nacional.

A partir de la reforma herreriana los contenidos de este curso volverían a estar en comunión con Roma tomando como base las enseñanzas de los principales juristas eclesiásticos ultramontanos de la época. Se planteaba la obligación de los obispos de obedecer al Papa, la universalidad de la Iglesia y la defensa de sus fueros y derechos en la sociedad. ${ }^{31}$ También se defendía el derecho de la Iglesia de poseer bienes, de percibir el diezmo, de la existencia de la jurisdicción eclesiástica, del ejercicio del derecho de asilo y de imponer sanciones y penas como la excomunión y el interdicto.

Otro de los objetivos de esta cátedra fue instruir esmeradamente a los alumnos en los aspectos históricos, sacramentales e institucionales de la Iglesia. Se estudiaron las fuentes y las nociones esenciales del derecho canónico: la Sagrada Escritura, los padres de la Iglesia, la tradición de la Iglesia, los concilios y los decretos de los Papas. La historia del derecho canónico, de la jerarquía eclesiástica, de los sacramentos, el culto y de las potestades de la Iglesia.

Finalmente, en cuanto a los cursos de ciencias, Herrera se preocupó porque la formación científica de sus alumnos estuviera al día con los últimos desarrollos de la época.

\section{Los métodos de enseñanza}

Herrera consideró que la transformación de los contenidos de los cursos era solo un aspecto de la reforma. Además del adelanto académico y profesional,

\footnotetext{
29 "Un conjunto de hombres que forman una raza aparte, que por su lengua, por su relijion y por sus hábitos, tienen mas semejanza y mas vínculos entre sí que con el resto del jénero humano". Bartolomé Herrera, Escritos y Discursos. t., 2, pp. 105-106.

30 "La sociedad de los que viven bajo unas mismas leyes y un mismo gobierno en un territorio propio". Bartolomé Herrera, Escritos y Discursos. t., 2, p. 107.

31 Con respecto a la infalibilidad papal el curso se limitó a presentar los argumentos a favor y los en contra, sin pronunciarse de manera definitiva debido a que aún no se había proclamado como dogma.
}

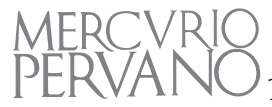


buscó que sus alumnos recibieran una formación integral, lo cual implicaba fomentar en ellos valores consistentes con los principios cristianos, forjar su disciplina y carácter, y desarrollar su capacidad dialéctica.

Para lograr estos objetivos se promovieron hábitos de estudio y, al mismo tiempo, se adoptó el método de enseñanza propio de la escolástica, se desterró el memorismo, y se desarrollaron técnicas para el debate y el razonamiento lógico. Las clases tendían a seguir la siguiente dinámica:

Después de exponer sus doctrinas [...] exigía de un alumno el resumen de lo explicado. A tal resumen seguía un examen minucioso del pro y del contra de lo acervado; examen en que se exprimía las condiciones dialécticas del carolino. $^{32}$

Según el historiador jesuita Rubén Vargas Ugarte, Herrera quiso que sus alumnos siguieran sus enseñanzas por la fuerza de la verdad y no por la imposición:

Se ha dicho que introdujo el dogmatismo en la enseñanza, pero allí están sus discípulos que sostendrán lo contrario. En su cátedra cada cual podía exponer con toda libertad sus ideas y en cuanto a sus enseñanzas no quería que los discípulos las aceptasen por provenir de su maestro, sino por las razones que se pesaban y discutían antes de suscribir a su parecer. ${ }^{33}$

Para habituar a los estudiantes en el debate intelectual se organizaron ejercicios literarios los cuales consistían en que todos los días, a la hora de la comida, un alumno debía recitar un capítulo de la ciencia que estudiaba y luego un condiscípulo debía hacerle objeciones hasta llegar a conclusiones sólidas. El catedrático debía resolver las dudas generadas y mantener el orden. ${ }^{34}$

En el reglamento se estipulaba que los superiores tenían el deber de guiar con destreza a los alumnos, ayudarlos a disipar sus errores e inspirarles "amor a la sólida virtud y pulir sus modales". ${ }^{35}$ Para ello, los superiores debían corregir en el acto toda falta contra la moral o contra la urbanidad, pero se exhortaba para que estas correcciones fueran hechas con prudencia antes que, con represión, a fin de que los alumnos comprendieran y asumieran sus errores. ${ }^{36}$

Cada mes se proponía un ejercicio literario para los alumnos de derecho, el cual consistía en que un estudiante de jurisprudencia debía hacer una

\footnotetext{
32 Jorge Guillermo Leguía, “Bartolomé Herrera, Maestro. Su labor en el Convictorio de San Carlos", en Bartolomé Herrera, Escritos y Discursos. t., 2, p. XXIII.

33 Rubén Vargas Ugarte, El Real Convictorio Carolino y sus dos luminarias. Lima, Carlos Milla Batres, 1970, p. 145.

34 BNP, D4698, "Proyecto de Reglamento para el Colegio de San Carlos", Lima, 1843, art. 101103.

35 BNP, D4698, "Proyecto de Reglamento para el Colegio de San Carlos", Lima, 1843, art. 6.

36 BNP, D4698, "Proyecto de Reglamento para el Colegio de San Carlos", Lima, 1843, art. 8.
} 
disertación sobre una materia determinada, habiendo tenido un mes para prepararla. Otro estudiante de derecho y un maestro o un catedrático debían presentar sus preguntas y objeciones, finalmente el alumno debía responder a las críticas y presentar su disertación al rector. ${ }^{37}$ Hubo un cuidado especial por parte del Rector de que estas discusiones no se convirtieran en estériles por la falta de fundamentos sólidos o por las rencillas que pudieran generarse. ${ }^{38}$

Asimismo, al finalizar el año académico los alumnos del último año se presentaban a exámenes públicos que se rendían ante las más altas autoridades del gobierno y de la Iglesia. ${ }^{39}$ Esta práctica hizo que San Carlos en los tiempos de Herrera se convirtiera en una importante instancia de debate público acerca de las doctrinas políticas y jurídicas que debían regir al país. Los alumnos que alcanzaban el primer puesto eran premiados por el ministro de educación y, en muchos casos, el presidente de la república lo invitaba a participar de distintos eventos junto con él. Se recuerda de manera especial el célebre examen que rindió José María de Irigoyen en diciembre de 1846, ante Benito Laso, Manuel Amunátegui y Agustín Charún, en el cual defendió brillantemente la doctrina de la soberanía de la inteligencia. ${ }^{40}$

No todos estuvieron de acuerdo con la metodología de Herrera. El ministro de gobierno, instrucción pública y beneficencia José Gregorio Paz Soldán criticó este sistema de enseñanza afirmando que los conocimientos así aprendidos se olvidaban rápidamente. Él abogaba por un retorno a la enseñanza memorista: "El estudio por comprensión, que en la actualidad se hace en algunos de esos establecimientos, no llena los fines de la enseñanza porque la ligera impresión que hace en el espíritu de los jóvenes, desaparece poco tiempo después de los exámenes, é inutiliza hasta cierto punto la notable consagración de los que enseñan y de los que aprenden. No sucede lo mismo recomendando a la memoria los principios elementales consignados en las obras que se adoptan para el estudio de las artes y de las ciencias [...]".41

De otro lado, se estableció un horario que tenía como fin generar hábitos de disciplina y orden, detallándose minuciosamente los deberes de los alumnos. Igualmente, respecto a las prácticas religiosas se establecieron espacios de oración y vida sacramental, incluyendo misa, rosario y preces diarias. Asimismo,

\footnotetext{
37 BNP, D4698, "Proyecto de Reglamento para el Colegio de San Carlos", Lima, 1843, art. 104-105.

38 “El Rector, el Vice-Rector o Catedrático que presidiere los Ejercicios dispuestos en los artículos anteriores cuidará esmeradamente de que se guarde en ellos moderación y urbanidad y de impedir que se introduzca el falso gusto de la sutileza y de embrollados raciocinios", en BNP, D4698, "Proyecto de Reglamento para el Colegio de San Carlos", Lima, 1843, art. 106.

39 BNP, D4698, "Proyecto de Reglamento para el Colegio de San Carlos", Lima, 1843, art. 107-111.

40 Raúl Porras Barrenechea, “José Antonio Barrenechea (1829-1889)”, en Boletín Bibliográfico, Lima, Universidad Mayor de San Marcos, 1928.

${ }^{41}$ El Peruano, Lima, 24 abril 1847.
}

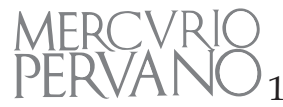


se buscó despertar la creatividad y la sensibilidad artística a través de los cursos de música, pintura y literatura. También se promovió y premió a los alumnos más destacados y era política del Colegio ayudar a aquellos que se encontraban en dificultades económicas.

A pesar del rigor que se implantó en el Convictorio, el régimen de San Carlos distó mucho de ser opresivo. Como bien afirmó Jorge Guillermo Leguía, San Carlos no fue una escuela correccional ${ }^{42}$, sino un ámbito en el cual la vida de los alumnos se desarrolló en un ambiente donde se combinaba la disciplina y el estudio, con la espontaneidad propia de la juventud y "el tradicional espíritu picaresco y bohemio de los colegiales", 43 la formación espiritual y religiosa con las discusiones doctrinarias, la sobriedad con la creatividad literaria y el espíritu romántico.

\section{El ocaso de la reforma educativa herreriana}

La labor educativa de Herrera en San Carlos no logró prolongarse en el tiempo debido a diversas causas. Una de ellas fue la discontinuidad en las políticas educativas de los gobiernos del país respecto a los centros de estudio dependientes del Estado. En segundo lugar, Herrera dejó el rectorado para dedicarse primero a la actividad política como ministro, diplomático y parlamentario. Luego, ejerció su ministerio pastoral como obispo de Arequipa durante los últimos cuatro años de su vida (1860-1864). Pero probablemente el obstáculo más serio que tuvo que enfrentar esta reforma fue la constante oposición política e intelectual de algunos influyentes grupos liberales. Ellos, conscientes de que San Carlos se había convertido en un poderoso centro de formación conservador y en uno de los principales establecimientos de educación superior del país, criticaron sus programas de estudio y buscaron por diversos medios controlar dicha institución. Asimismo, favorecieron al Colegio Guadalupe el cual era un importante reducto liberal que contaba con algunos prominentes políticos en su planta docente, como era el caso de los hermanos José y Pedro Gálvez, antiguos discípulos de Herrera que luego fueron críticos de las ideas de su antiguo maestro.

A pesar de ello, el hecho que Herrera continuara ejerciendo un papel protagónico en el gobierno como Ministro de Beneficencia, Instrucción Pública, Justicia y Negocios Eclesiásticos (hasta 1852) y como parlamentario (hasta 1860), permitió que sus ideas continuaran vigentes en la institución, aunque de manera intermitente. En este sentido, San Carlos siguió los lineamientos intelectuales de la época de Herrera hasta el rectorado de Evaristo Gómez Sánchez, uno de sus más fieles discípulos.

\footnotetext{
42 Jorge Guillermo Leguía, “Bartolomé Herrera, Maestro. Su labor en el Convictorio de San Carlos", en Bartolomé Herrera, Escritos y Discursos. t., 2, págs. XXVI-XXVII.

${ }^{43}$ Ibidem.
} 
Esta situación cambió efímeramente en 1855 pues luego de la caída del gobierno de José Rufino Echenique, hubo un predominio liberal en la Convención Nacional (1855-1857). Durante esos años se promulgó un nuevo reglamento de instrucción pública que creó una nueva instancia de control de la educación en el país: la Dirección General de Estudios. Las atribuciones que tuvo esta entidad le permitieron al Estado tener un minucioso control sobre la educación nacional. Su competencia se extendía a todos los establecimientos educativos de la república y podía intervenir directamente en la reforma de los colegios, los contenidos de los programas de estudio y la selección de los catedráticos. Los miembros de la Dirección General de Estudios fueron Manuel Villarán y Loli (director), Sebastián Lorente (inspector) y Francisco Rosas (secretario). ${ }^{44}$

Bajo el amparo de este nuevo marco legal, en abril de 1855 se formó una Comisión Inspectora de los establecimientos de instrucción pública que debía reformar al Convictorio según las instrucciones del gobierno. ${ }^{45}$ José Gálvez fue nombrado rector de San Carlos. Él procuró conservar los adelantos científicos de la institución, pero, al mismo tiempo, iniciar una transformación ideológica en sus aulas. ${ }^{46}$ No obstante, los objetivos de Gálvez solo se lograron parcialmente debido a que en 1856 tuvo que dejar el rectorado para dedicarse a la activad política. Durante su breve gestión algunos de los antiguos catedráticos fueron reemplazados provisionalmente por otros de tendencias liberales. ${ }^{47}$ Gálvez mismo fue profesor de derecho constitucional, de gentes y penal, José Silva Santisteban de derecho natural y legislación ${ }^{48}$ y Sebastián Lorente de literatura.

En 1857 el presidente Ramón Castilla empezó a alejarse de los sectores liberales hasta el punto que disolvió la Convención Nacional en noviembre de ese año. Como resultado de dicho distanciamiento, Manuel Ferreyros fue nombrado como nuevo Director General de Estudios y Antonio Arenas como rector de San Carlos, quien previamente había sido vicerrector en los tiempos de Herrera. Arenas buscó reorientar a San Carlos según las líneas intelectuales herrerianas. Para ello, estableció un nuevo plan de estudios que reformaba el régimen interno del colegio. Al mismo tiempo restituyó a algunos profesores herrerianos como Pedro José Calderón y Manuel Irigoyen. Reaccionando frente a estas acciones, la Convención Nacional desarrolló una labor de fiscalización, exigiendo revisar cada uno de los textos adoptados por el Colegio, "y en

\footnotetext{
${ }^{44}$ El Peruano, Lima, 11 abril 1855.

45 El Peruano, Lima, 3 abril 1855.

${ }^{46}$ Jorge Basadre, Historia de la República del Perú. Lima, Ediciones Historia, 1961, tomo 3, pp. 1327-1330.

${ }_{47}$ Los nombres de los nuevos profesores están en: El Peruano, Lima, 3 abril 1855.

48 José Silva Santisteban fue un admirador de las ideas liberales y atacó las ideas de Herrera. En 1856 publicó "Curso de Derecho constitucional" y luego algunos manuales de derecho internacional, civil, práctica forense y otras materias. En: JoRGE BASADRE, Historia de la República del Perú. t., 3. Lima, Ediciones Historia, 1961. págs.1330.
}

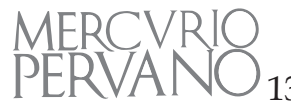


particular las de Filosofía y de todos los ramos del Derecho" e investigar el estado en que se hallaban las reformas del Convictorio. ${ }^{49}$

En 1857, Arenas renunció al rectorado, el cual fue asumido por un antiguo discípulo de Herrera, José Antonio Barrenechea (junio de 1857) y el vicerrectorado por Pedro José Calderón (septiembre de 1857) ${ }^{50}$ y Daniel Ruso. Estos nuevos nombramientos iban en contra de los planes de la Convención Nacional respecto al Convictorio. El hecho que Pedro José Calderón, un prominente conservador, enseñara los importantes cursos de religión y derecho canónico produjo recelos entre los principales líderes liberales del momento. Ello motivó a que se cuestionara la competencia de los profesores carolinos y que se los acusara de enseñar "doctrinas antirrepublicanas". Por esta razón, la estrategia de la Convención fue recortar sistemáticamente el presupuesto de esta entidad hasta el punto que Barrenechea estuvo a punto de cerrar sus aulas. El rector denunció que las causas de los problemas económicos del Convictorio fueron la desaparición de algunas rentas, el entorpecimiento de otras y el aumento de los gastos. Acusaba a la Convención Nacional de intervenir directamente en el recorte del presupuesto del Convictorio y de impedir que los decretos del ejecutivo, que buscaban financiar a la institución, se pudieran aplicar. Estas acciones, junto con el decidido apoyo que la Convención brindó al colegio Guadalupe, fue una muestra de la intencionalidad política que hubo en las medidas educativas de la época. ${ }^{51}$ Una vez disuelta la Convención, el Convictorio experimentó una inmediata, aunque leve recuperación económica, y mayor libertad en el desarrollo de sus programas de estudio.

Durante los siguientes años, San Carlos estuvo dirigido por el deán Juan Gualberto Valdivia quien fue rector entre 1858 y 1866 y mantuvo cierto equilibrio entre liberales y conservadores. Así, por ejemplo, Luis Benjamín Cisneros, de clara filiación liberal, fue nombrado catedrático de derecho natural, constitucional y de gentes, y, por otro lado, Pedro José Calderón lo fue de los cursos de Derecho eclesiástico, Derecho económico y Religión.

La prensa de tendencia liberal, en especial El Constitucional y El Liberal, reanudó su crítica contra Calderón por defender ideas políticas afines a las de Herrera, por cuestionar al regalismo y por defender el primado del Papa y la independencia de la Iglesia en sus asuntos internos frente al poder político. En esta misma línea, dos destacados parlamentarios liberales, Francisco Javier

\footnotetext{
${ }^{49}$ El Peruano, Lima, 9 septiembre 1857.

${ }^{50}$ Pedro José Calderón asumió el vicerrectorado el 30 de junio de 1857, reemplazando a Manuel Irigoyen.

51 Los testimonios de la tensión entre el rector Barrenechea y la Convención Nacional están en los expedientes del Archivo General de la Nación de Lima: AGN. Archivo del Ministerio de Justicia (Instrucción), Legajo 180 y AGN. Dirección General de Estudios. Años 1855-1865, Legajo 192.
} 
Mariátegui y Francisco de Paula González Vigil, ${ }^{52}$ exigieron su destitución acusándolo nuevamente de propagar "doctrinas antirrepublicanas" contrarias a los intereses de la nación. ${ }^{53}$ A pesar de estos ataques, Calderón continuó en San Carlos hasta 1865.

El fin de la influencia de Herrera en San Carlos se dio entre 1865 y 1866 cuando el Convictorio fue incorporado a la Universidad de San Marcos bajo el gabinete ministerial "Gálvez" durante la dictadura liberal de Mariano Ignacio Prado (1865-1868). Tanto José Gálvez, presidente del Gabinete, como José Simeón Tejeda (ministro de Justicia, Instrucción y Beneficencia), impulsaron esta reforma educativa. Es importante resaltar que, desde 1861, el influyente político liberal José Gregorio Paz Soldán era rector de San Marcos. Así, cuando en 1866 las facultades de San Carlos se incorporaron a la Universidad de San Marcos, ellas tuvieron entre sus principales autoridades a otros destacados liberales: Pedro Gálvez fue decano de la facultad de derecho donde, además, enseñaron el radical Mariano Amézaga (Derecho romano), Luciano Benjamín Cisneros (Derecho filosófico) y Juan Francisco Pazos (Derecho internacional positivo). El decano de la facultad de letras fue Juan Gualberto Valdivia, quien fue catedrático de Fundamentos de la religión. Sebastián Lorente enseñó en esta facultad la cátedra de Filosofía trascendental. ${ }^{54}$

En este sentido, como bien señala Víctor Andrés Belaunde:

Por la reforma del 61 al 66, destruido el carácter disciplinario de San Carlos, revividos los estudios superiores libres de la universidad, diferenciada de la instrucción media de la instrucción facultativa, se inicia por influencia de maestros como Lorente y Gálvez una nueva orientación que podría llamarse liberal. Y es liberal en dos sentidos: primero en el sentido de la abolición de la disciplina colegial, del estricto régimen del internado; y en segundo lugar, en el sentido de las ideas que la alentaron..$^{55}$

Después de la Guerra del Pacífico el liberalismo sería desplazado por el positivismo en San Marcos: "A la universidad liberal del año 66 y del 76 ha sustituido después de la Guerra, la universidad positiva o positivista". 56

\footnotetext{
${ }^{52}$ Francisco Javier Mariátegui (1793-1884) fue un destacado miembro de la masonería peruana y un activo intelectual, político y diplomático. De otro lado, Francisco de Paula González Vigil (1792-1875), sacerdote católico excomulgado por Pío IX, fue probablemente el más influyente político e intelectual liberal y regalista en el Perú durante el siglo diecinueve.

53 Testimonios de esta campaña contra Pedro José Calderón se pueden encontrar en trece números del periódico El Constitucional, Lima, mayo-junio 1858.

${ }^{54}$ El Peruano, Lima, 7 abril 1866.

55 Víctor Andrés Belaunde, La vida universitaria. Lima, Okura, 1987, p. 4.

56 Ibid., p. 12.
} 


\section{Influencia de la reforma herreriana en la esfera pública peruana}

A pesar de que Herrera tuvo que enfrentar la oposición de poderosos grupos políticos, la reforma del Convictorio de San Carlos dio frutos. A lo largo de los diez años en que ejerció el rectorado logró forjar a una generación de discípulos. Si bien no todos sus alumnos siguieron sus orientaciones doctrinarias, la mayor parte reconoció la importancia de San Carlos en su formación. Algunos de ellos, como los hermanos Pedro y José Gálvez, y Luciano Benjamín Cisneros adoptaron el liberalismo como credo político y se convirtieron en los principales opositores de su antiguo maestro. Sin embargo, fueron numerosos los discípulos que acogiendo las ideas de Herrera tuvieron una intensa participación en la vida política del país. También contribuyó decisivamente en la renovación del catolicismo peruano, no solo porque algunos de los alumnos carolinos fueron luego destacados obispos y sacerdotes sino porque también contribuyó a la formación de un laicado comprometido, y ayudó a generar una línea de continuidad en el pensamiento católico nacional que se prolongó en Víctor Andrés Belaunde y José de la Riva Agüero.

También la reforma herreriana repercutió como un modelo educativo en otros centros de estudios, generalmente dirigidos por ex-alumnos o por cooperadores de Herrera, en los cuales aplicaron muchos de los elementos de su reglamento y programas. Ejemplo de ello fueron los casos del Seminario de Santo Toribio, del Seminario San Jerónimo de Arequipa y de los Colegios de Cajamarca, de Ica y de Huánuco. ${ }^{57}$

En esta línea, Raúl Porras Barrenechea enfatizó los logros educativos de Herrera:

Ninguna generación, seguramente, salió de San Carlos con convicciones más firmes y claras, y con ideas más definidas sobre las grandes cuestiones políticas del país y sobre los conflictos del Derecho de gentes que la educada por Herrera. Ninguna se halló por lo tanto mejor preparada para la vida pública. A los pocos años de egresada del Convictorio, aquella juventud, y llegada al periódico y a la cátedra, al escaño parlamentario o al sillón ministerial, se hacía clásica la lucidez y el acierto, la profunda cultura jurídica con que los discípulos de Herrera discutían cuestiones políticas de soberanía, de patronato o de competencia entre los poderes públicos o cuestiones internacionales sobre la extensión de la jurisdicción o la territorialidad..$^{58}$

\footnotetext{
${ }^{57}$ El Seminario Santo Toribio fue dirigido por Juan Ambrosio Huerta, muy afín a las ideas de Herrera, y luego por José María Lozano, antiguo discípulo del rector carolino. Otros discípulos de Herrera fueron el padre Amador Sotomayor fue rector del colegio nacional de Huánuco, y Mariano Leocadio García (antiguo catedrático en San Carlos) fue rector del Colegio Nacional San Luis Gonzaga en Ica.

58 Raúl Porras Barrenechea, "José Antonio Barrenechea (1829-1889)", en Boletín Bibliográfico, Lima, Universidad Mayor de San Marcos, 1928.
} 
Es necesario destacar que, a pesar de las limitaciones del pensamiento y de la obra de Herrera, sus acciones buscaron una renovación cívica, moral y espiritual del país. Como bien señala Jorge Guillermo Leguía:

La historia recordará siempre con gratitud su generoso y perseverante esfuerzo en pro de la cultura, que fue un patriota desvelado que ofrendó a una idea sus mejores horas y hasta su salud; ....... que no representó sólo un gran cerebro sino también un gran carácter, en esta tierra de veleidosos y de abúlicos; y que, por su intenso fervor confesional, provocó la más importante agitación ideológica que jamás contemplara nuestra nacionalidad. ${ }^{59}$

\section{Fuentes Primarias}

\section{Archivo General de la Nación (AGN) (Lima, Perú)}

AGN. Archivo del Ministerio de Justicia (Instrucción) (1825-1842) Convictorios Bolívar y San Carlos. "Expediente de visita del Colegio de San Carlos-1842", Legajo 179.

AGN. Archivo del Ministerio de Justicia (Instrucción), Legajo 180.

AGN. Dirección General de Estudios. Años 1855-1865, Legajo 192.

\section{Biblioteca Nacional del Perú (BNP)}

BNP, D4698, "Proyecto de Reglamento para el Colegio de San Carlos", Lima, 1843.

\section{Colección Félix Denegri Luna - Instituto Riva-Agüero - PUCP}

Colegio de San Carlos, Tabla para el examen a que se presentan los alumnos del Colegio San Carlos. Lima, Imprenta del Colegio, Lima, 1843.

Colegio de San Carlos, Tabla para el examen a que se presentan los alumnos del Colegio San Carlos. Lima, Imprenta del Colegio, Lima, 1846.

Colegio de San Carlos, Tabla para el examen a que se presentan los alumnos del Colegio San Carlos. Lima, Imprenta del Colegio, Lima, 1848.

\section{Periódicos}

El Constitucional (1858)

El Peruano $(1843,1847,1855,1857,1866)$

\footnotetext{
59 Jorge Guillermo Leguía (1924) "San Carlos en los días de Herrera", en Boletín Bibliográfico, Lima, Universidad Mayor de San Marcos (diciembre 1924), pág. 203.
} 


\section{Bibliografía}

Álvarez Calderón, Carlos, "Bartolomé Herrera y la Soberanía de la Inteligencia", Derecho PUCP 7 (1947), pp. 32-50;

Asís, Agustín de, Bartolomé Herrera, pensador político. Sevilla, Escuela de Estudios Hispano-Americanos, 1954.

BASADRE, Jorge, Historia de la República del Perú. t., 3. Lima, Ediciones Historia, 1961.

BRADING, David. Orbe indiano: de la monarquía católica a la República criolla, 1492-1867, México, D.F., Fondo de Cultura Económica, 1991.

CARrasco, Eduardo, Calendario y Guía de Forasteros de la República Peruana, Lima, Imprenta de Instrucción primaria, 1843.

Cubas Ramacciotti, Ricardo, "Educación, elites e independencia: El papel del Convictorio de San Carlos en la emancipación peruana", en Scarlett O’Phelan (ed.), La Independencia del Perú: De los Borbones a Bolívar. Lima: Pontificia Universidad Católica del Perú, Instituto Riva-Agüero, 2001, pp. 289-317.

- - , "Herrera como educador: La reforma del Convictorio de San Carlos" en Fernán Altuve (comp.) Bartolomé Herrera y su tiempo. Lima, Sociedad Peruana de Historia - Editorial Quinto Reino, 2010, pp. 35-54.

EsPinOZA, Grover Antonio, “Despotismo Ilustrado y reforma educativa: El Real Convictorio de San Carlos de Lima entre 1770 y 1817" (Tesis de Licenciatura), Lima, Pontificia Universidad Católica del Perú, 1996.

- - " "La reforma de la educación superior en Lima: el caso del Real Convictorio de San Carlos", en Scarlett O'Phelan Godoy (ed.), El Perú en el siglo XVIII: la Era Borbónica. Lima: Pontificia Universidad Católica del Perú, Instituto Riva-Agüero, 2015, págs. 205-244.

GóNGORA, Mario, “La Ilustración, el Despotismo Ilustrado y la crisis ideológica en las colonias", en Mario Góngora, Estudios sobre la historia colonial hispanoamericana. Santiago de Chile, Editorial Universitaria, 1998, pp. 161-200.

HERr, Richard, España y la revolución del siglo XVIII. Madrid, Aguilar, 1964.

Herrera, Bartolomé, Escritos y Discursos vol. 2, Lima, E. Rosay, 1934.

-—, Tratado de Lógica. Arequipa, Imprenta del colegio Seminario de San Jerónimo, 1871.

-—, Tratado de Teodicea. Arequipa, Imprenta del colegio Seminario de San Jerónimo, 1872. 
Herrera, Gonzalo y Rodrigo Herrera, "Biografía de Don Bartolomé Herrera”, en: Bartolomé Herrera, Escritos y Discursos, vol. 1, Lima, E. Rosay, 1929, p. XXXI.

Huaraj, Juan Carlos, "Izando velas hacia Ítaca: Estatuto del Convictorio de San Carlos de Lima, 1829-1839", en Investigaciones Sociales, 13, 22 (2009), pp. 283-299.

Klaiber, Jeffrey, La Iglesia en el Perú. Lima: Fondo Editorial de la Pontificia Universidad Católica del Perú, 1988.

Leguía, Jorge Guillermo, "San Carlos en tiempos de Herrera" en Boletín Bibliográfico de la Universidad de San Marcos, 1, 15 (diciembre, 1924), pp. 191-204.

LoAyza Pérez, Alex, La política educativa del Estado peruano y la propuesta educativa de los Colegios San Carlos y Guadalupe. Lima, Universidad Mayor de San Marcos, 2006.

Porras BarrenecheA, Raúl, “José Antonio Barrenechea (1829-1889)", en Boletín Bibliográfico, Lima, Universidad Mayor de San Marcos, 1928.

SARrailH, Jean, La España ilustrada de la segunda mitad del siglo XVIII. México, Fondo Cultura Económica, 1974.

VALLE, Fernando, “Teología, filosofía y derecho en el Perú del XVIII: Dos reformas ilustradas en el Colegio de San Carlos de Lima (1771 Y 1787)", en Revista Teológica Limense, 40, 3 (2006), pp. 337-382.

Vargas Ugarte, Rubén, El Real Convictorio de San Carlos y sus dos luminarias. Lima, Carlos Milla Batres, 1970. 